\title{
TREATMENT OF HÆMORRHAGE
}

\author{
PBOM \\ PUNCTURED WOUNDS OF THE THROAT AND \\ NECK,
}

ESPECIALLY CONSIDERED WITH REGARD TO LIGATURE

OF THE EXTERNAL CAROTID ARTERY.

BY

WILLIAM HARRISON CRIPPS, F.R.C.S., BURGEON TO THE GREAT NORTHERN HOSPITAL, ASEISTANT SURGEON TO THE ROYAL FREE HOSPITAL.

(Received Jauuary 31st-Read April 23rd, 1878.)

THE violence of all bleedings in these localities, the suddenness of their occurrence, and the rapidity with which they prove fatal, surround this subject with grave interest. It is, indeed, in these cases of emergency that some of the most brilliant triumphs of surgery have been achieved. In ordinary incised wounds the treatment of hæmorrhage scarcely admits of discussion, ligature of the bleeding vessels in situ being the obvious treatment. It will be in the following circumstances that difficulties may arise.

1. Punctured wounds behind and below the angle of the jaw.

2. Punctured wounds through the mouth.

3. Hæmorrhage after removal of tonsils. 
4. Hæmorrhage from cancer of the mouth and tongue.

5. Secondary hæmorrhage after wounds or surgical operations.

Fortunately in many of these cases the treatment is sufficiently clear. In some instances the wound may be enlarged with good prospect of securing the vessel. The careful and accurate adjustment of pressure may succeed. Cold and astringents have been usefully employed. In one or two cases the ingenuity of the surgeon has suggested a ready remedy, such, for instance, as in a case of secondary hæmorrhage after operating for cleft palate, in which $\mathrm{Mr}$. Savory permanently arrested the bleeding by a wooden plug in the posterior palatine canal.

However successful these means have proved in many cases, there will remain a certain proportion in which their use has been employed in vain, or in which the very nature of the wound renders the application hopeless from the first.

The search for the wounded vessel is at times anatomically impossible, and even in accessible situations in secondary hæmorrhage it is a proceeding not unlikely to fail. In these cases surgeons have resorted to ligature of the main vessel in continuity, as the only practical means likely to prevent bleeding and prolong life.

The vessel almost universally selected is the common carotid, and the object of this paper is to investigate the facts bearing on this question.

In the appendix will be found a Table of fifty cases in which the common carotid has been tied for hæmorrhage, these cases being the result of a search through the English papers and reports, together with a few. of the leading American journals. These cases have been in no way selected, and merely represent the total number found recorded. Many of these have been published in previous statistics, while some have not been previously tabulated. Statistics drawn from published records must always be received with caution, for successful cases probably find their way more readily into print than the failures. I think, 
therefore, that the mortality in these should be taken as presenting a minimum rate. This suspicion is somewhat confirmed by finding that in hospital statistical reports in which all cases are recorded the death ratio is considerably higher. Out of the fifty cases collected twenty-eight died, or 56 per cent.

This mortality closely corresponds to that given in the tables of Pilz and Norris, and, I think, may be taken as fairly near the truth.

These tables show clearly that the operation of ligature of the common carotid artery must be classed amongst the most fatal in surgery.

The cause of this high rate of mortality will now be considered, and the following table shows the number of deaths arranged under five headings.

\section{Causes of death in 28 cases.}

\begin{tabular}{|c|c|c|c|c|c|}
\hline Brain sympt & $\mathrm{ms}$ & & - & & cases. \\
\hline Recurrent he & morrhage & fr & ind & - 8 & \\
\hline Secondary $\mathbf{h}$ & emorrhag & $\mathrm{s}$ & gature & . 1 & " \\
\hline Dyspnœa & - & • & . & . 1 & " \\
\hline Exhaustion & - & $\cdot$ & . & . 5 & $"$ \\
\hline Not stated & - & $\bullet$ & . & . 5 & " \\
\hline & Total & & . &.$\overline{28}$ & " \\
\hline
\end{tabular}

Eight of these deaths, or 28 per cent., were directly consequent upon the operation and not attributable in any way to the accident for which the operation was performed.

Eight deaths took place in consequence of continued bleeding from the original wound after ligature of the common trunk, proving the futility of the operation; six cases remain, in which death probably took place from causes disconnected with ligature of the carotid artery.

It is hardly within the province of this paper to consider in detail the cause of the brain symptoms, and for present purposes it is sufficient to state that interference with the nutrition of the brain from obliteration of one of the internal 
carotids is the direct cause of the phenomena. From Dr. James Russel's admirable papers in the 'Medical Times and Gazette,' 1874, it would appear that the brain symptoms are somewhat in proportion to the amount of blood lost previous to the operation, and that a brain already anæmic from general hæmorrhage is less able to support the sudden cutting off of the supply than one in a previously healthy condition. The second leading cause of mortality (recurrence of hæmorrhage from original wound) requires a more detailed consideration.

Assuming for reasons which will be subsequently explained, that the ressel originally wounded is the external carotid, or one of its branches, it becomes a matter of considerable importance to consider from which end of the wounded vessel the bleeding proceeds. Unfortunately in scarcely any of the cases collected has any note been made on this point. In two instances, however, it is stated that the blood came as a regurgitant stream from the proximal end. In the majority of instances, ligature of the common carotid temporarily arrested the bleeding; this could hardly have been the case had the blood come from the distal end. The following anatomical and experimental facts point to the same conclusion.

Blood obeying the same law as other fluids, will escape in the direction of least resistance. The large vessels at the base of the brain connecting the internal carotid both with its fellow of the opposite side and the vertebrals, would appear to offer less resistance to the blood current than is offered by the exceedingly fine anastomoses of the superficial vessels across the middle line. So fine are these anastomoses in the linguals, that Hyrtl doubts whether they anastomose at all; and the specimen here shown (specimen No., Path. series, 8.4, St. Bartholomew's Museum), in which a fine coloured fluid injected into one lingual has failed to cross the middle line snpports his view. The following experiment bears upon this point:

In the dead body the right carotid is ligatured, and on the same side one or two of the branches of the external 
carotid are divided, for example, the lingual and facial, at a distance of one inch from the main trunk. If water be now injected into the common carotid of the opposite side, it will be found that nearly all the water flows out through the proximal end of the divided vessel of the right side ; that this arises principally through the anastomoses of the internal carotid as a regurgitant stream can be shown by placing a ligature upon the internal carotid of the right side, the effect of which is to cause the flow from the proximal end of the cut vessel almost entirely to cease.

The anastomoses of the superior thyroid appear to be freer than those of the other branches of the exterual carotid, and this is principally due to its free communications with deeper vessels of its own side. This vessel is probably an important channel of communication after ligature of the carotid. The following case mentioned by Guthrie bears upon this point:"During an operation at Westminster Hospital, the external carotid was opened a little above its bifurcation. A ligature was placed upon the common carotid; the bleeding was not in the least arrested. A ligature was then placed upon the external carotid above the wound; it still continued to pour out blood. A third ligature was placed upon the internal carotid without success. The external carotid was then ligatured just below the wound, but beyond the superior thyroid, when the bleeding ceased.

Notwithstanding the fact that in the majority of instances the bleeding takes place through the proximal end, it seems probable that in some cases it may be the distal end of the wounded vessel that furnishes the blood. Except upon this hypothesis it is difficult to explain the phenomenon that has been especially mentioned in three cases (Nos. 4, 41, 50), namely, that when the ligature on the common carotid was tightened, an increased gush of blood immediately took place from the wound.

Something might be ascertained in the way of diagnosis by observing the effect of pressure upon the carotids of either side alternately.

Having shown how a large proportion of the deaths are 
directly due to brain symptoms caused by ligature of the common carotid, and seeing how often the operation has proved futile in preventing death by bleeding from the original wound, it would appear that in the face of these facts most cogent reasons would be required to justify its continuance. This justification could only be found in the firm belief that surgery offered no other resource to avert an inevitable death. Such is not the case, for in ligature of the external carotid will be found an effectual alternative to the operation upon the common trunk.

The objections raised to this operation are as follows :

1st. The fear of secondary hæmorrhage from the seat of ligature due to close proximity of its larger branches.

2ndly. The futility of the operation should the wounded vessel be the internal carotid.

3rdly. That it is less easy to ligature than the primitive carotid.

The fear of secondary hæmorrhage must be a theory entirely grounded upon the anatomical arrangement of the carotid and its branches, and disappears altogether before the test of actual experience.

M. Guyon, in 'Mémoires de la Société de Chirurgie,' vol. vi, mentions twenty-seven cases in which the external carotid had been ligatured. 1 Some of these occurred in wounds, others either in continuity before surgical operation, or on accidental section during their performance. To this number I can add three cases. In only a single instance did secondary hæmorrhage occur. Thirty cases are doubtless too small a number upon which to venture any accurate estimate as to the frequency of this accident. But that it only occurred once in thirty times is evidence that the external carotid may be reckoned as amongst the least liable of all the large vessels to bleeding at the seat of ligature.

To the second objection the answer lies in an appeal to the fact of how rare is a wound of the internal carotid compared

1 Amongst these are included cases by Maisonneuve and Chassaignac, fuller details of which will be found in the 'Bulletin de la Société de Chirurgie,' Tom. I. 
with that of the external or its branches. In eighteen cases in which the bleeding vessel was identified, the following were the vessels wounded :

\begin{tabular}{|c|c|c|c|c|}
\hline Common carotid at & point & 11 & & . 2 \\
\hline External carotid & . & - & 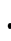 & \\
\hline Lingual . & • & ․ & & \\
\hline Facial . & - & • & & \\
\hline Tonsillar branch & . & - & & \\
\hline Branch in parotid $g$ & yland & . & & \\
\hline Ascending pharyng & & • & & \\
\hline Internal maxillary & - & • & & \\
\hline Inferior dental & . & • & & \\
\hline Middle meningeal & - & • & & \\
\hline Vertebral . & - & • & & \\
\hline Internal carotid & $\therefore$ & • & & \\
\hline External also wounc & & • & & \\
\hline Close to bifurcation & & • & & \\
\hline & Cotal & 列 & & \\
\hline
\end{tabular}

The internal carotid was found only to have been wounded twice alone, and once in conjunction with the external. In many cases of wounds and operations about the tonsils the internal carotid was supposed to have suffered, but in the majority of instances the vessel had proved to be a branch of the external carotid. It cannot be denied, however, that wounds of the internal carotid have occurred, and that in these cases a ligature on the external carotid would be useless. In the event of the mistake occurring it is not beyond remedy, for a ligature might still be placed upon the internal at the bifurcation of the common carotid. On the other hand no remedy can be found for a patient dying with hemiplegia caused by obstructing the internal carotid on account of a wound of the external.

Taking this into consideration, and bearing in mind the relative frequency of either mistake, I do not think it can be urged as a serious objection to ligature of the external carotid.

The last objection, that the vessel is more difficult to find, requires no comment.

In favour of the operation the following reasons may be powerfully urged: 
1stly. That circulation through the brain is not the least interfered with. Consequently, one large element of danger is avoided.

2ndly. That the danger of recurrent hæmorrhage from the wound must be diminished in proportion to the number of cases in which it occurs from the proximal end, as a regurgitant stream through the internal carotid or through the superior thyroid.

3rdly. That the incision made over the external carotid will also expose the bifurcation and internal carotid, and may thus lead to a direct exposure of the wounded vessel. (See Cases Nos. 4, 7, 18).

It now remains to be considered upon what portion of the external carotid the ligature can be best applied. From a considerable number of measurements $I$ find that, in about half, the superior thyroid arises almost immediately after the bifurcation of the primitive trunk, and very rarely at a greater distance than half an inch. In most bodies will be found an interval from half an inch to three quarters of an inch between the origin of the superior thyroid and lingual, and a point situated midway between these vessels offers the best site for ligature. If during the operation the lingual appears low down in the wound, probably the safest course would be to place a ligature around it.

In conclusion I would state, that this paper is not meant to advocate ligature of the external carotid artery as an ordinary operation for hæmorrhage, but as a substitute for that of the common carotid, and as a procedure only to be had recourse to in cases of emergency, after all simpler means have been tried in vain. 
PUNCTURED WOUNDS OF THE THROAT AND NECK.

237

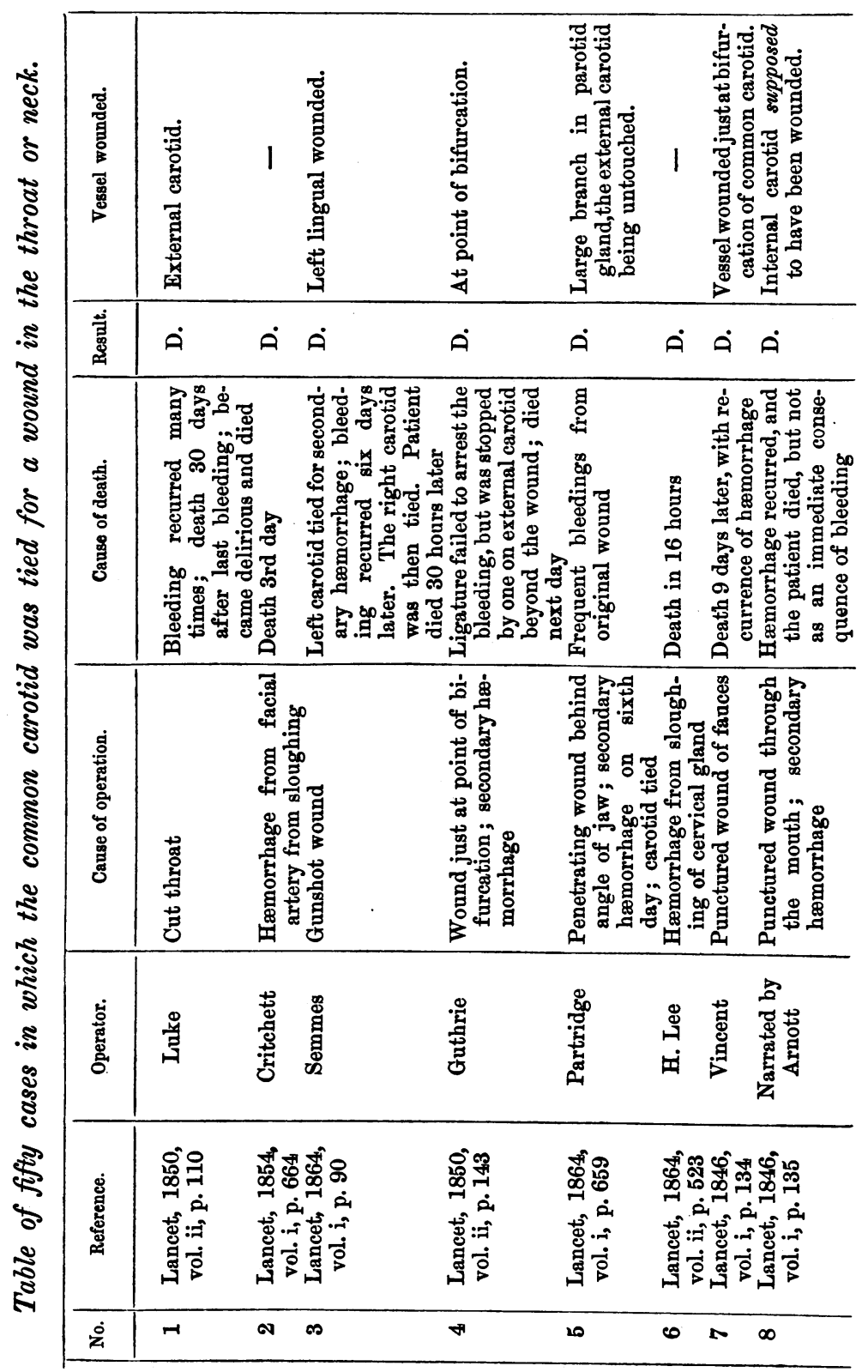




\begin{tabular}{|c|c|c|c|c|c|c|c|c|c|c|c|c|c|}
\hline \multirow{2}{*}{ 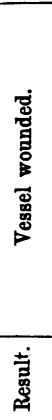 } & \multicolumn{5}{|c|}{ 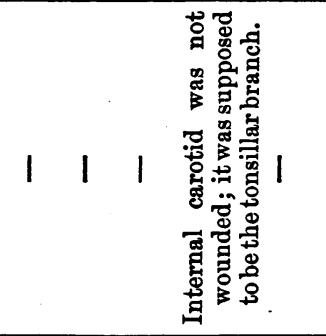 } & 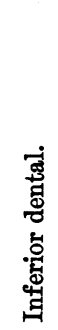 & \multicolumn{2}{|c|}{ 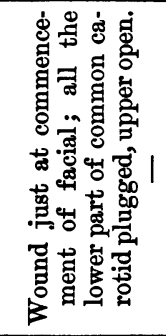 } & \multirow[t]{2}{*}{ 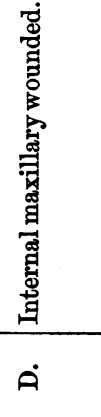 } & \multicolumn{2}{|c|}{ 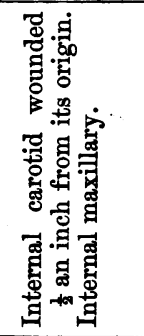 } & \multirow{2}{*}{ 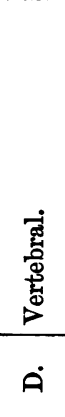 } & \multirow{2}{*}{ 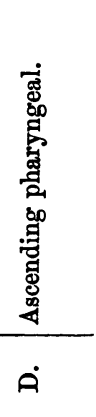 } \\
\hline & $\dot{a}$ & $\dot{A}$ & $\dot{A}$ & $\dot{A}$ & $\dot{A}$ & $\dot{\theta}$ & $\dot{A}$ & $\dot{A}$ & & $\dot{A}$ & $\dot{A}$ & & \\
\hline 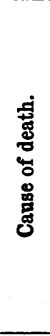 & 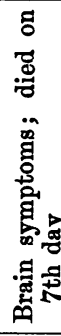 & 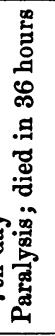 & 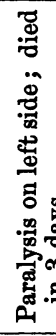 & 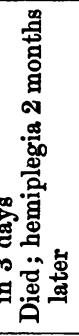 & 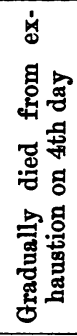 & 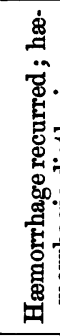 & 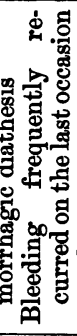 & 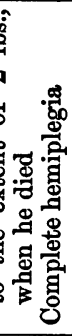 & 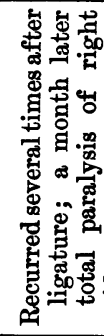 & 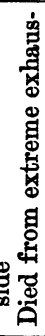 & 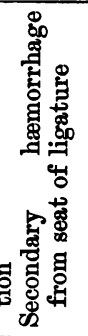 & 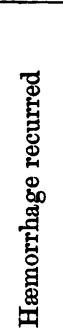 & 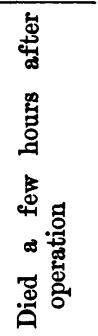 \\
\hline 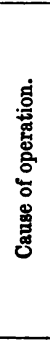 & 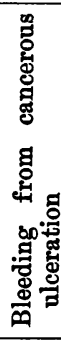 & 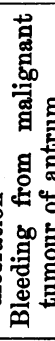 & 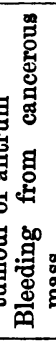 & 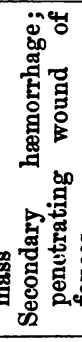 & 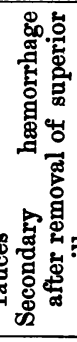 & 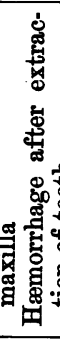 & 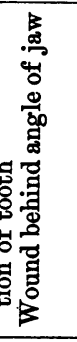 & 1 & 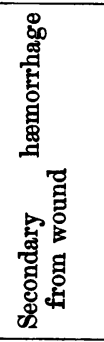 & 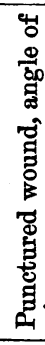 & 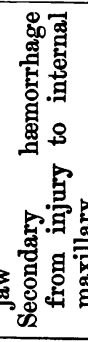 & 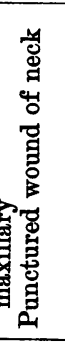 & 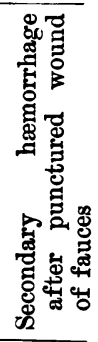 \\
\hline 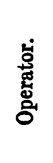 & 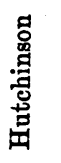 & 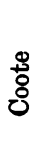 & 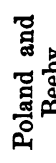 & 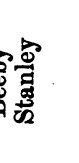 & 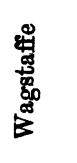 & 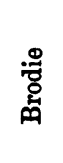 & 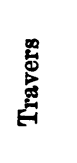 & 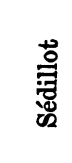 & ఫ్ & $\begin{array}{l}\text { 岁 } \\
\text { 总 } \\
\text { 出 }\end{array}$ & 1 & 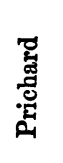 & 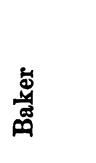 \\
\hline 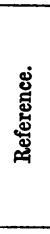 & 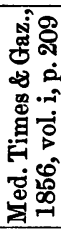 & 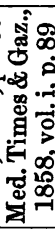 & 作 & 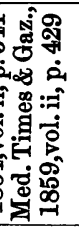 & 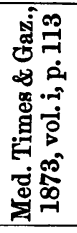 & 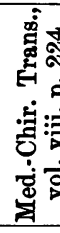 & 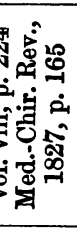 & 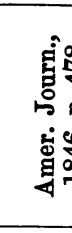 & 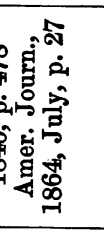 & & 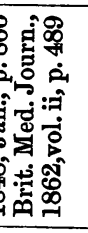 & $\begin{array}{l}50 \\
0 \\
0\end{array}$ & 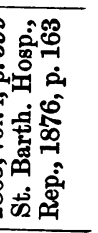 \\
\hline 㕕 & o & 욱 & $\Rightarrow$ & 고 & $\stackrel{m}{\rightarrow}$ & $\underset{-}{-}$ & $\stackrel{20}{\sim}$ & $\bar{\sigma}$ & $\vec{r}$ & 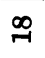 & $\pi$ & ণ & $\vec{a}$ \\
\hline
\end{tabular}


PUNCTURED WOUNDS OF THE THROAT AND NECK. 239
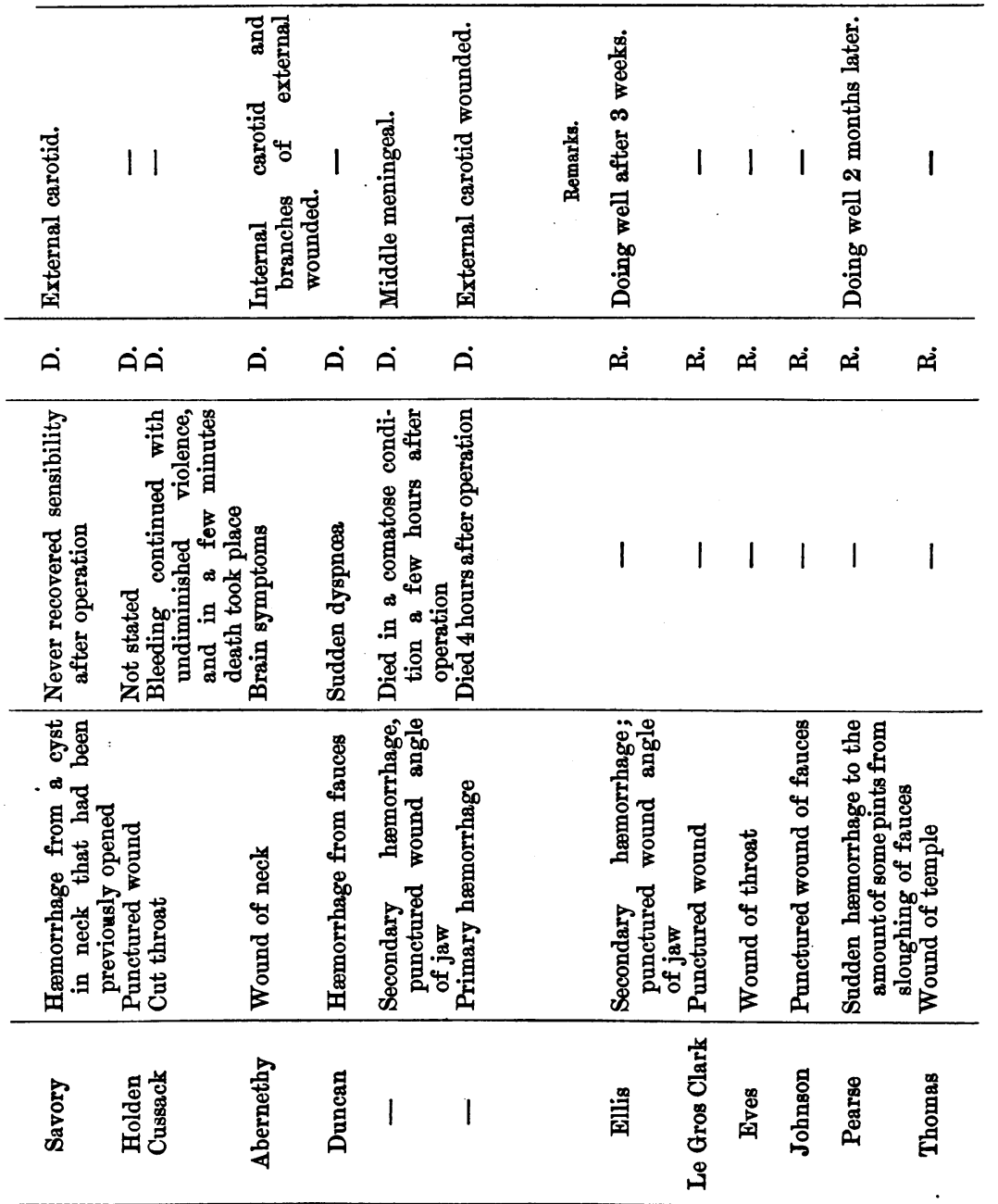

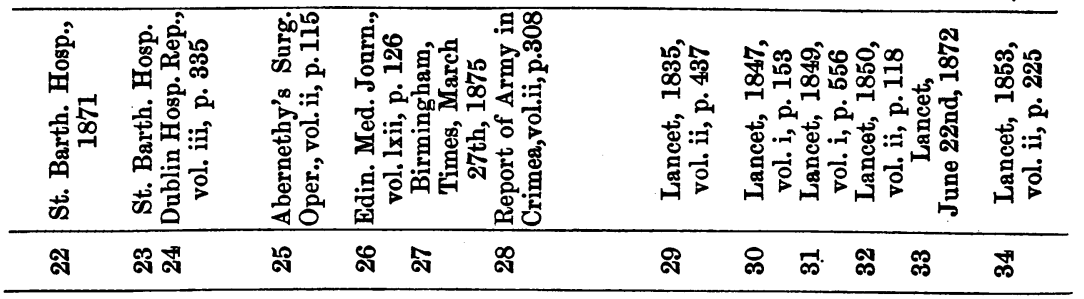




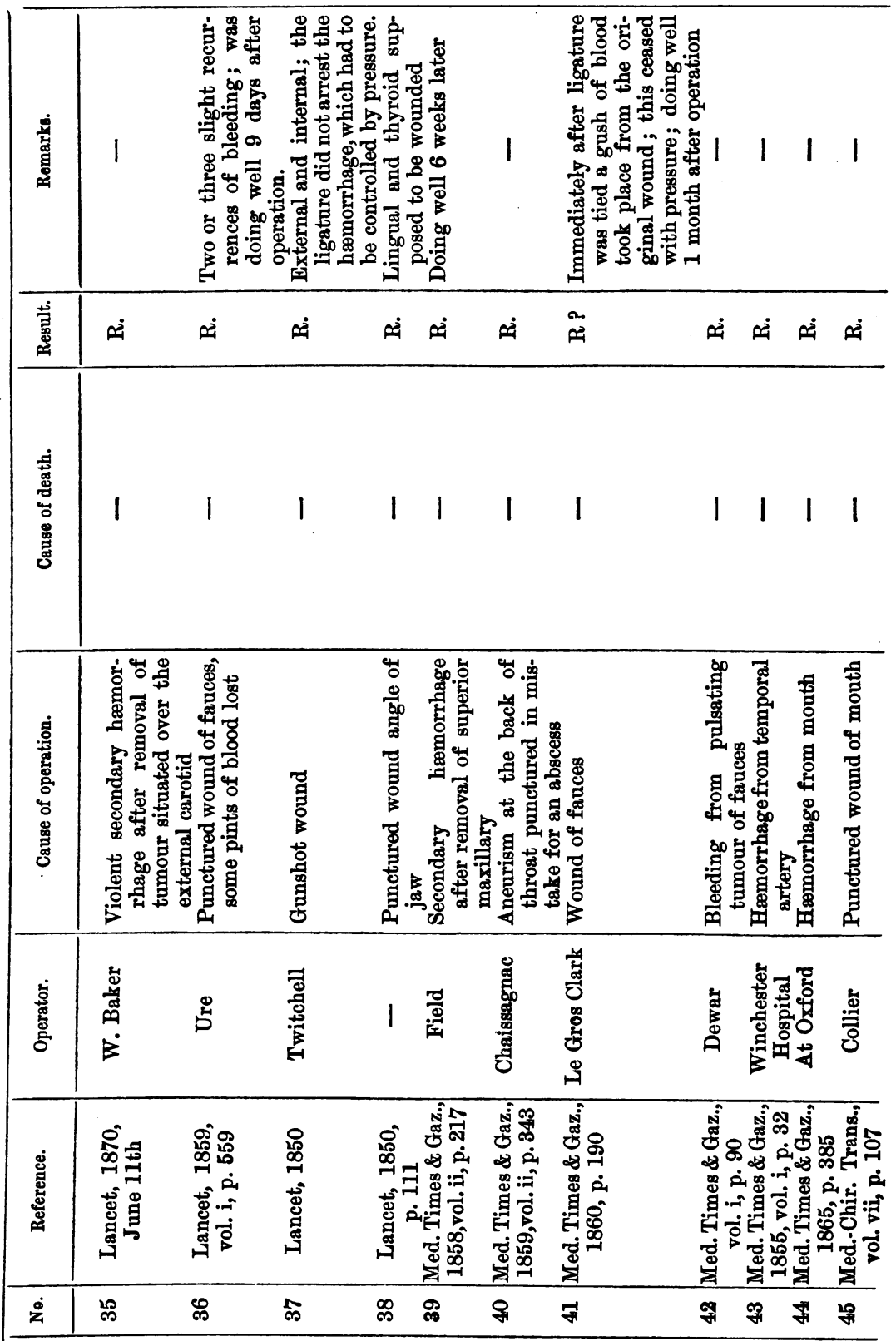


PUNCTURED WOUNDS OF THE THROAT AND NECK, 241

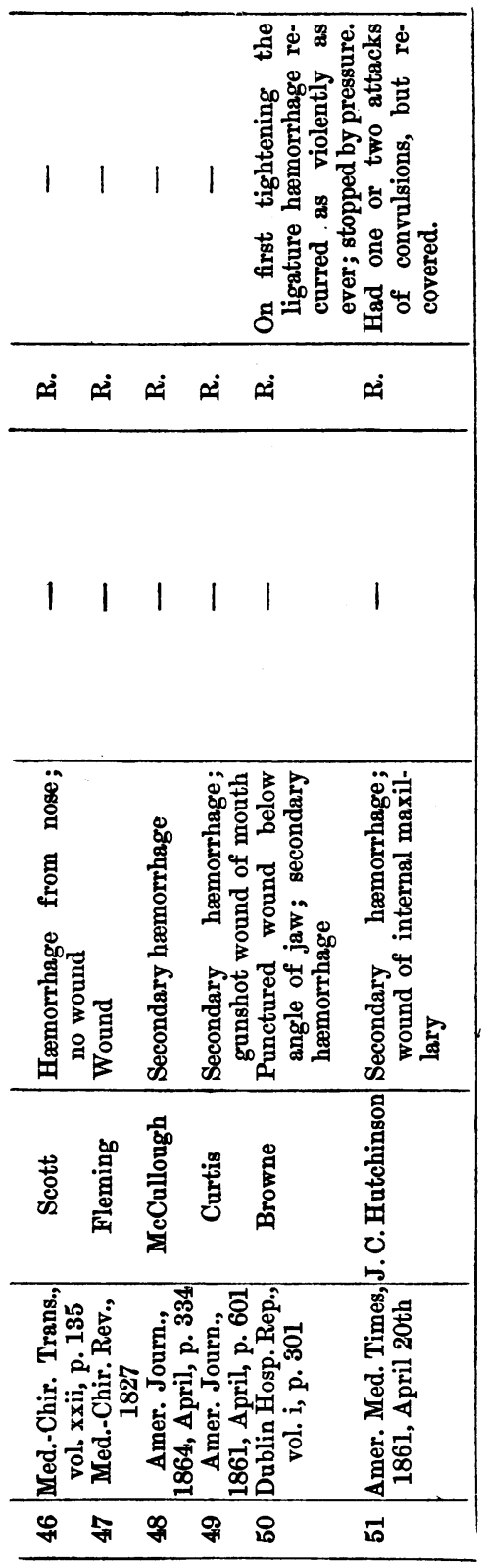

VOL. LXI. 